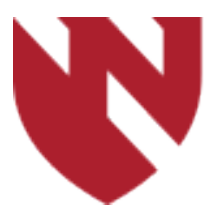

December 2019

\title{
Delirium Assessment for Acute Ischemic Stroke Patients at UNMC
}

Haeyoung Baang

University of Nebraska Medical Center

T. Scott Diesing

University of Nebraska Medical Center

Daniel L. Murman

University of Nebraska Medical Center

Tell us how you used this information in this short survey.

Follow this and additional works at: https://digitalcommons.unmc.edu/gmerj

Part of the Higher Education Commons, and the Medicine and Health Sciences Commons

\section{Recommended Citation}

Baang, H., Diesing, T., , Murman, D. L. Delirium Assessment for Acute Ischemic Stroke Patients at UNMC. Graduate Medical Education Research Journal. 2019 Dec 13; 1(1).

https://digitalcommons.unmc.edu/gmerj/vol1/iss1/19

This Conference Proceeding is brought to you for free and open access by DigitalCommons@UNMC. It has been accepted for inclusion in Graduate Medical Education Research Journal by an authorized editor of DigitalCommons@UNMC.For more information, please contact digitalcommons@unmc.edu. 


\section{Delirium Assessment for Acute Ischemic Stroke Patients at UNMC}

Creative Commons License

(c) (i) ()

This work is licensed under a Creative Commons Attribution-Noncommercial-No Derivative Works 4.0 License. 
Conclusions: Renal sympathetic vasomotion monitoring could provide intraprocedural feedback for interventionists performing renal denervation and serve more broadly as a platform technology for the evaluation and treatment of diseases affecting the

sympathetic nervous system.

https://doi.org/10.32873/unmc.dc.gmerj.1.1.017

\section{Proceedings of the 1st Annual Graduate Medical Education Research Symposium | Poster Presentation Winners}

\section{Different Strokes for Different Folks: Trends in Elective Surgery for Diverticular Disease}

Rishi Batra, Matt Fuglestad, Brad Hall, Jiangtao Luo, Jennifer Leinick, Sean Langenfeld

Mentor: Sean Langenfeld

Program: General Surgery

The approach to patients with sigmoid diverticulitis has evolved towards more conservative management regardless of initial presentation or number of episodes. Despite this trend, approximately $20 \%$ of patients with diverticulitis will still require surgical intervention. It is unknown how the approach for diverticular disease has changed with the increasing popularity of new operative platforms.

The purpose of this study was to evaluate recent trends in elective surgery for diverticulitis, patient demographics, and outcomes.

The American College of Surgeons National Surgical Quality Improvement Program Colectomy Procedure-Targeted Database was queried from 2012 to 2016 . This clinical database allows for direct identification of different minimally invasive techniques (laparoscopic/LAP, laparoscopic hand-assist/ LHA, robotic/RC, single-incision/SILS). Patients with ICD-9/ICD-10 diagnoses codes for diverticular disease of the large intestine were identified and stratified by operative approach (12,697 cases).

Patients undergoing open colectomy were older, had higher ASA class, and had higher rates of comorbidities. BMI and race were similar except for SILS. Robotic colectomies increased yearly from 2012-2016 (P < 0.0001 ), while LAP cases declined. However, there was not an increase in the overall use of minimally invasive techniques LAP/LHA/ $\mathrm{RC} / \mathrm{SILS}$ ). Robotic-assisted operations took significantly more time as compared to all other approaches $(\mathrm{P}<0.001)$, but had a lower conversion rate when compared to LAP/LHA. Anastomotic complications were highest in

\section{Delirium Assessment for Acute Ischemic Stroke Patients at UNMC Hae Young Baang, T. Scott Diesing, Daniel L. Murman}

Mentor: Daniel L. Murman

Program: Neurology

Background \& Objectives: To investigate incidence of delirium in acute ischemic stroke patients at the University of Nebraska Medical Center (UNMC) and identify associated factors with development of delirium in acute ischemic stroke.

Methods: This is a prospective observational study. We screened delirium daily for patients aged 18 or older admitted with acute ischemic stroke using Confusion Assessment Method for the ICU and 3-minute Diagnostic Confusion Assessment Method starting within 48 hours after recognition of stroke until post-stroke day 7 or discharge. Data on patient characteristics were collected through chart review and analyzed using multivariate logistic regression.
Results: Of 74 patients included in the study, 29 (39.1\%) developed delirium. The mean age and NIH stroke scale (NIHSS) at presentation were higher in delirium group than non-delirium group $(69.4 \pm 2.76 \mathrm{vs}$ $65.1 \pm 2.00,13.0 \pm 1.30$ vs $7.1 \pm 1.00)$. Also, delirium group showed higher rates of prolonged ICU stay, presence of aphasia, embolic stroke, bilateral cerebral involvement, history of previous stroke and cognitive decline compared with non-delirium group. In contrast, more patients in non-delirium group received intravenous antithrombotic therapy. However, only the associations with NIHSS (OR $=1.26,95 \%$ CI 1.10 to $1.44, \mathrm{P}<$ $0.01)$ and intravenous antithrombotic therapy $(\mathrm{OR}=0.04,95 \% \mathrm{CI} 0.00$ to $0.35, \mathrm{P}<0.01)$ were statistically significant.

Conclusions: This pilot study demonstrated high incidence of delirium among acute converted group. Patients undergoing open operations (planned or converted) stayed significantly longer compared to other approaches $(\mathrm{P}<0.001)$, had higher rates of 30 -day readmission $(\mathrm{P}<0.001)$, and were less likely to be discharged directly to home $(\mathrm{P}<$ 0.001 ). Minimally invasive techniques have remained the preferred method for elective diverticular disease; however, a growing percentage of cases are being performed with a robotic approach. Robotic-assisted surgery had a lower conversion rate at the expense of longer operative times.

https://doi.org/10.32873/unmc.dc.gmerj.1.1.018

ischemic stroke patients at UNMC. Further studies with a larger sample size are required to identify risk factors of delirium in this patient population and proactively manage it for better outcomes.

https://doi.org/10.32873/unmc.dc.gmerj.1.1.019 